\title{
DESIGN AND FABRICATION OF PAPER RECYCLING UNIT
}

\author{
Aditya Vinod Pillai \\ RWTH Aachen University, Germany \\ Monu George Varghese \\ RWTH Aachen University, Germany \\ Davis Jose \\ RWTH Aachen University, Germany
}

\begin{abstract}
In any big institution, especially educational institutions like schools or colleges, generation of large quantity of waste papers is quite apparent. And effective use of recycled paper is also possible (craft papers, registers etc). So, instead of disposing off the waste papers into trash, recycling them makes sense. This not only helps the institute in cost saving but will also ensure its contribution towards the protection of the environment. Designing manually operated small-scaled paper recycling plant, which can be used in schools and colleges, ensures that a cheap and non-complex method of production of paper product is guaranteed. Accordingly design of the machine unit has been prepared with all necessary component specifications.
\end{abstract}

Keywords: paper, fabrication, recycling, craft papers, waste paper, environment

Cite this Article: Aditya Vinod Pillai, Monu George Varghese and Davis Jose, Design and Fabrication of Paper Recycling Unit. International Journal of Mechanical Engineering and Technology 11(2), 2020, pp. 32-44.

https://iaeme.com/Home/issue/IJMET?Volume $=11 \&$ Issue $=2$

\section{INTRODUCTION}

Paper is one of the most important products ever invented by man. The primary raw material for the paper production is the pulp fibers obtained by complicated chemical process from natural materials, mainly from wood. This fiber production is very energy demanding and at the manufacturing process there are many of the chemical matters which are very problematic from the viewpoint of the environment protection. The paper recycling, simplified, means the repeated defibering, grinding and drying, when the mechanical properties of the secondary stock are altered, the chemical properties of fibers, the polymerization degree of pulp polysaccharide components, mainly of cellulose, their super molecular structure, the morphological structure of fibers, range and level of interferes bonds. Paper recycling saves the natural wood raw stock, decreases the operation and the capital costs to paper unit, decrease water consumption and last but not least this paper processing gives rise to the 
environment preservation. A key issue in the paper recycling is the impact of the energy use in manufacturing.

\section{LITERATURE REVIEW}

A considerable effort is now being expended to increase the utilization of recycled or secondary fibers in a variety of grades of paper and board. Recycled fiber is, without some form of mechanical and/or chemical treatment, inferior in performance to virgin fiber. One manifestation of this is the difference in performance of never dried and market pulps, although one does not regard the latter as recycled fiber. A market pulp has experienced little or no refining, but when subjected to refining can develop properties comparable with a neverdried beaten pulp. In addition to the common refining effects, i.e., internal and external fibrillation, fines generation, etc., an important refining action for a market pulp is the removal of kinks and curl, which are responsible for the initial increase in sheet strength. The kinks and curl arise from high consistency processing, and unrestrained drying on the paper machine or in flash drying processes. The major difference between a market pulp and recycled fiber is that prior to recycling the fibers have generally been subjected to a significant level of refining. The more refining the fiber has received the greater the effects of drying or horrification. Furthermore, in addition to drying or horrification, the furnish may be contaminated by stickies, surfactants, starch, wet strength agents, printing inks, and adhesives. It is presumed that ineffective strategies for removal of these contaminants can lead to a further degradation of the pulp's papermaking potential. There is little published data in this area, and the focus of attention has been mainly on deinking of various grades of paper and the achievement of satisfactory optical properties.

A recycled furnish also differs from a virgin or market pulp furnish in as much as there may be a high level of fines present. In many operations using recycled fiber, the fines which are considered to be only an inert filler material are removed to become a component of sludge or landfill. Fines utilization and management have become important issues due to increasing demands for recycled fiber usage and mill closure. There is extensive literature on the subject of recycling. This literature review is not intended to be all-inclusive, but where relevant some general sources are referenced. The Institute of Paper Science and Technology has produced two useful

Bibliographic Series on "Reclaimed Fibers," the last of which was issued in 1983. More recently, TAPPI Press 1990 has published two volumes of collected papers on the subject of "Recycling Paper", and part of Volume 3, in the TAPPI/CPPA series devoted to Pulp and Paper Manufacture, deals with secondary fiber usage. A recent publication by TAPPI "Secondary Fiber Recycling" also deals with various recycling topics. Some of the technical issues of recycling have been reviewed by de Ruvo and Htun and more recently by Howard.

These issues include changes in properties due to repeated cycling, factors affecting the recycle potential of a pulp, papermaking variables, i.e., refining, wet pressing, drying, calendaring, and chemical additives. The reviews also considered strategies for recovery of the pulp's papermaking potential. A number of researchers McKee, Bovin, Hartler, and Teder, Bobalek and Charturvedi, and Howard and Bichard have examined property changes with repeated cycling. The general findings are well-known, and one can conclude that there is a general loss in strength properties with the exception of tear which usually increases. It is important to know what the likely level of recycling is within furnish, and this will obviously depend on the level of recycled fiber utilization one wants to achieve. 


\section{PROBLEM INDENTIFICATION}

\subsection{The Importance of Paper Recycling}

"Recycled paper produces $73 \%$ less air pollution than if it was made from raw materials. 10 million tonnes of paper and cardboard are used annually in the India. The average person in the UK gets through $10 \mathrm{~kg}$ of newspapers per year. It takes 24 trees to make 1 ton of newspaper.

"It takes 7 days for a recycled newspaper to come back as a newspaper again. $40 \%$ of the paper and cardboard used in the India is recovered for recycling

Only $20 \%$ of paper is recycled from paper waste yearly which is fairly low compared to other developed countries.

These figures emphasize just why paper recycling is so important and why we should all be doing all we can to recycling some, if not all our paper waste.

It doesn't have to be difficult to recycle paper and the positive effect recycling has on the environment far outweighs the small effort needed to implement paper recycling throughout your business.

Whether you are an office where recycling bins can be installed and waste paper collected regularly for recycling or a large-scale waste paper producer such as a publisher where a baler, be it single chamber, multi-chamber or mill-sized baler can be easily installed to safely store and bale your paper waste ready for recycling.

\section{DESIGN}

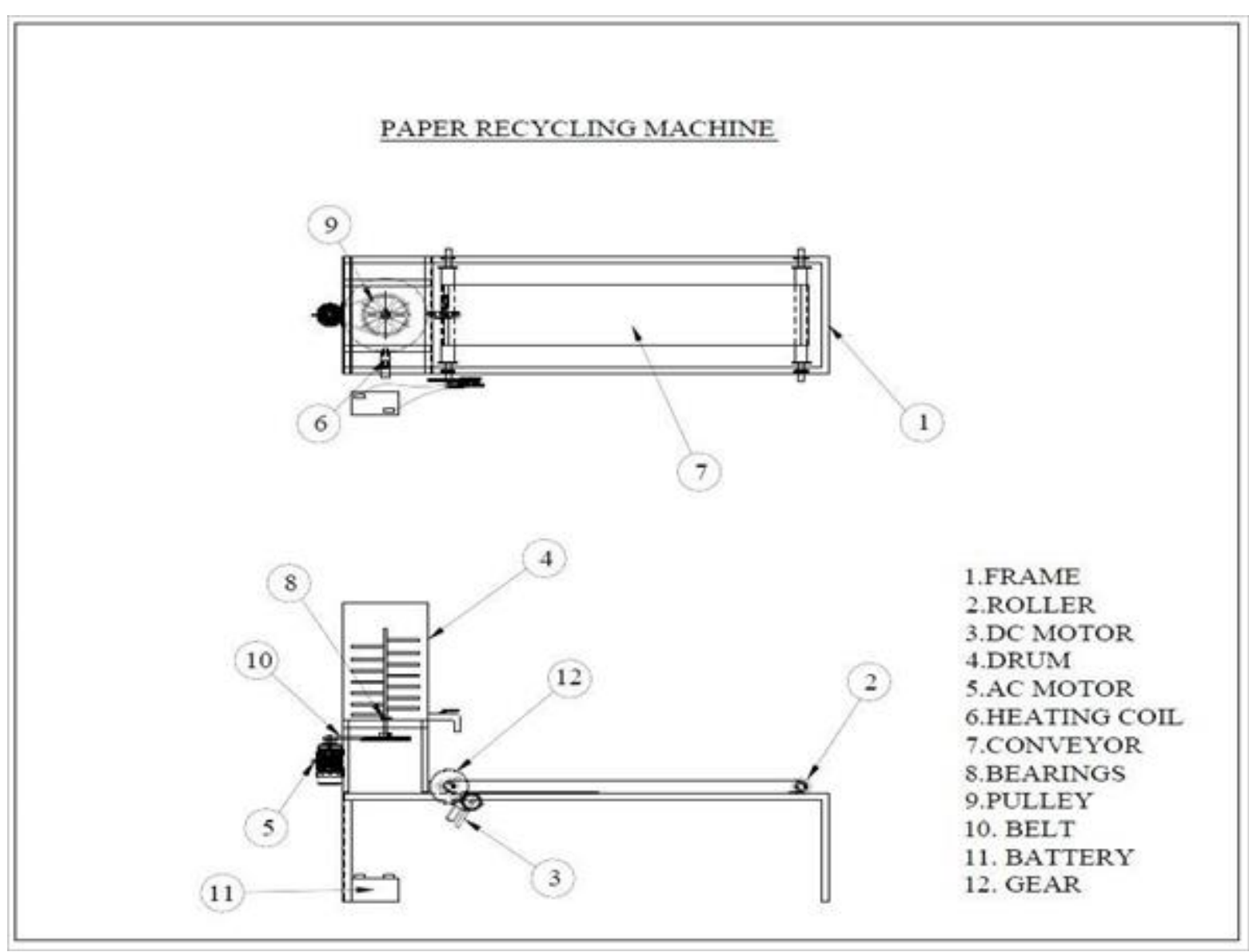

Figure 1 Basic Design 

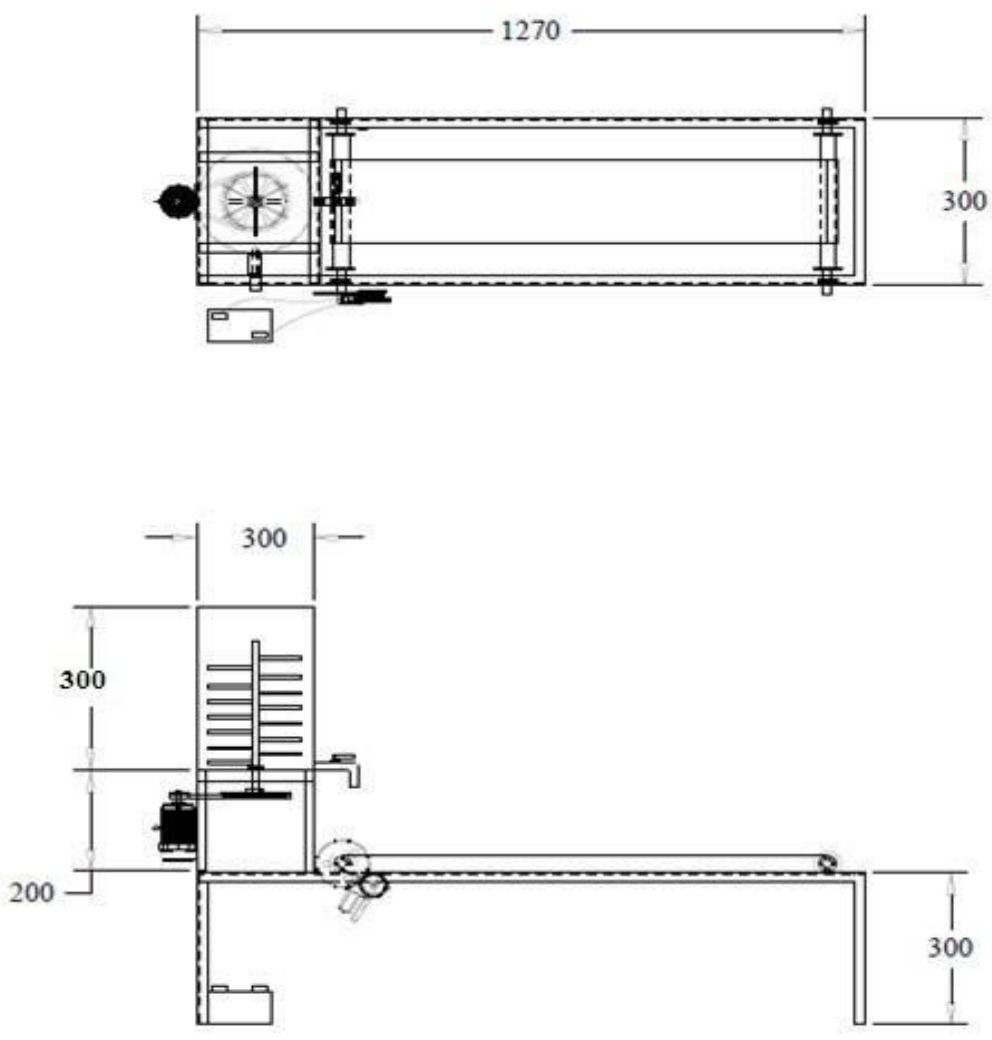

Figure 2 Basic Design

\section{COMPONENTS AND DESCRIPTION}

The major components involved in the paper recycling machine are as follows.

- Frame

- De motor

- Battery

- Bearings

- Spur gear

- AC motor

- Pulley

- Belt drive

- Conveyor belt

- Roller

- Gate valve 


\subsection{Frame}

This is made of mild steel material. The whole parts are mounted on this frame structure with the suitable arrangement. Boring of bearing sizes and open bores done in one setting so as to align the bearings properly while assembling. Provisions are made to cover the bearings with grease.

\subsection{Motor}

An electric motor is a machine which converts electrical energy to mechanical energy. Its action is based on the principle that when a current-carrying conductor is placed in a magnetic field, it experiences a magnetic force whose direction is given by Fleming's left-hand rule.

When a motor is in operation, it develops torque. This torque can produce mechanical rotation. DC motors are also like generators classified into shunt wound or series wound, or compound wound motors.

\subsection{Battery}

In isolated systems away from the grid, batteries are used for storage of excess solar energy converted into electrical energy. The only exceptions are isolated sunshine load such as irrigation pumps or drinking water supplies for storage. In fact, for small units with output less than one kilowatt.

Batteries seem to be the only technically and economically available storage means. Since both the photo-voltaic system and batteries are high in capital costs. It is necessary that the overall system be optimized with respect to available energy and local demand pattern. To be economically attractive the storage of solar electricity requires a battery with a particular combination of properties:

- Low cost

- Long life

- High reliability High overall efficiency

- Low discharge

- Minimum maintenance

- Ampere hour efficiency

- Watt hour efficiency

- We use lead acid battery for storing the electrical energy from the solar panel for lighting the street and so about the lead acid cells are explained below.

\subsection{Bearing with Bearing Cap}

The bearings are pressed smoothly to fit into the shafts because if hammered the bearing may develop cracks. Bearing is made up of steel material and bearing cap is mild steel.

However, such bearings cannot be used indiscriminately without a careful study of the loads and operating conditions. In addition, the bearing must be provided with adequate mounting, lubrication and sealing. 

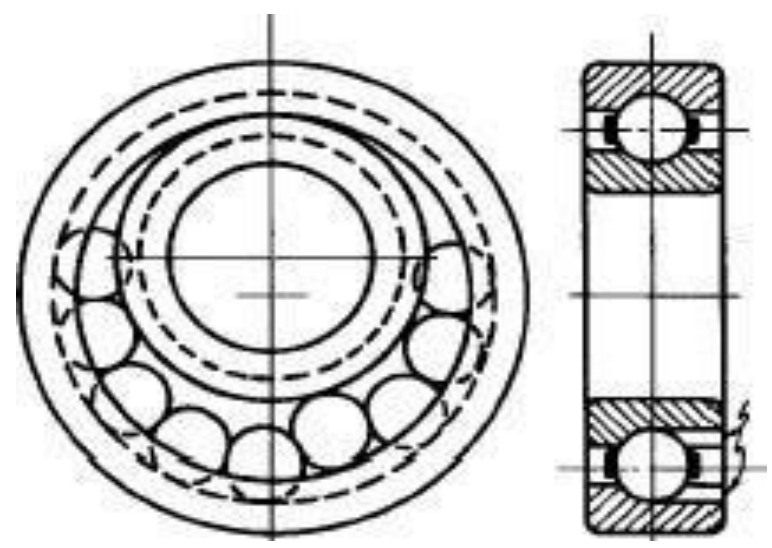

Figure 3 bearing

\subsection{AC Motor}

An $\mathrm{AC}$ motor is an electric motor driven by an alternating current (AC). The AC motor commonly consists of two basic parts, an outside stationary stator having coils supplied with alternating current to produce a rotating magnetic field, and an inside rotor attached to the output shaft producing a second rotating magnetic field. The rotor magnetic field may be produced by permanent magnets, reluctance saliency, or DC or AC electrical windings.

Less commonly, linear AC motors operate on similar principles as rotating motors but have their stationary and moving parts arranged in a straight-line configuration, producing linear motion instead of rotation.

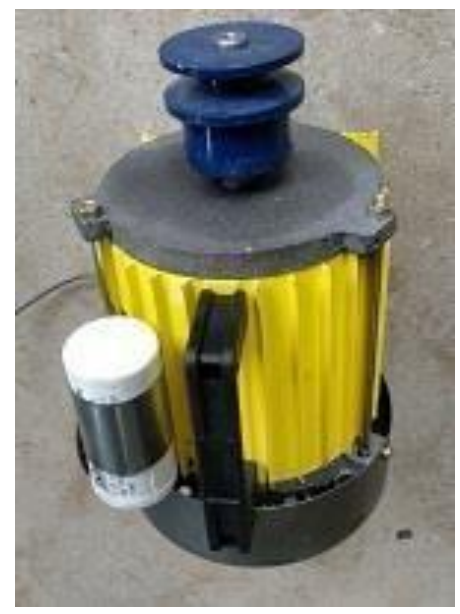

Figure 4 AC Motor

\subsection{Pulley}

A pulley is a wheel on an axle or shaft that is designed to support movement and change of direction of a cable or belt along its circumference. Pulleys are used in a variety of ways to lift loads, apply forces, and to transmit power. In nautical contexts, the assembly of wheel, axle and supporting shell is referred to as a "block." A pulley may also be called a sheave or drum and may have a groove between two flanges around its circumference. The drive element of a pulley system can be a rope, cable, belt, or chain that runs over the pulley inside the groove. Hero of Alexandria identified the pulley as one of six simple machines used to lift weights. Pulleys are assembled to form a block and tackle in order to provide mechanical advantage to 
apply large forces. Pulleys are also assembled as part of belt and chain drives in order to transmit power from one rotating shaft to another.

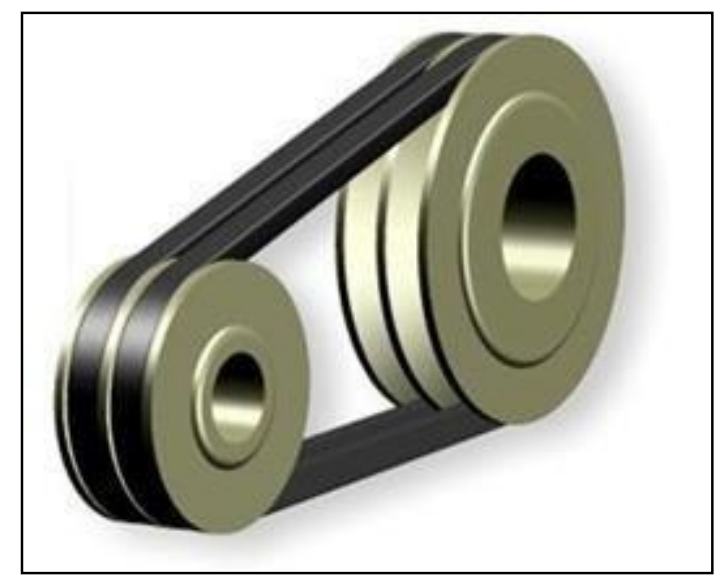

Figure 5 Pulley

\subsection{Belt Drive}

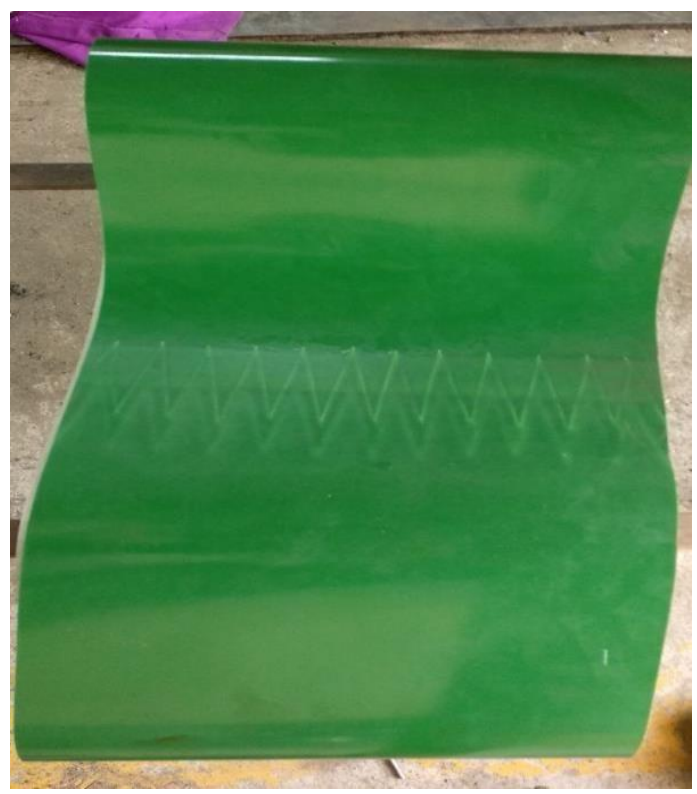

Figure 6 Belt Drive

A belt is a loop of flexible material used to mechanically link two or more rotating shafts, most often parallel. Belts may be used as a source of motion, to transmit power efficiently or to track relative movement. Belts are looped over pulleys and may have a twist between the pulleys and the shafts need not be parallel. In a two pulley system, the belt can either drive the pulleys normally in one direction (the same if on parallel shafts) or the belt may be crossed, so that the direction of the driven shaft is reversed (the opposite direction to the driver if on parallel shafts). As a source of motion, a conveyor belt is one application where the belt is adapted to continuously carry a load between two points. A conveyor belt is the carrying medium of a belt conveyor system (often shortened to belt conveyor). A belt conveyor system is one of many types of conveyor systems. A belt conveyor system consists of two or more pulleys (sometimes referred to as drums), with an endless loop of carrying medium-the 
conveyor belt that rotates about them. One or both of the pulleys are powered, moving the belt and the material on the belt forward. The powered pulley is called the drive pulley while the unpowered pulley is called the idler pulley. There are two main industrial classes of belt conveyors; Those in general material handling such as those moving boxes along inside a factory and bulk material handling such as those used to transport large volumes of resources and agricultural materials, such as grain, salt, coal, ore, sand, overburden and more.

\subsection{Belt Conveyor}

A conveyor belt is the carrying medium of a belt conveyor system (often shortened to belt conveyor). A belt conveyor system is one of many types of conveyor systems. A belt conveyor system consists of two or more pulleys (sometimes referred to as drums), with an endless loop of carrying medium the conveyor belt that rotates about them. One or both of the pulleys are powered, moving the belt and the material on the belt forward. The powered pulley is called the drive pulley while the unpowered pulley is called the idler pulley. There are two main industrial classes of belt conveyors; Those in general material handling such as those moving boxes along inside a factory and bulk material handling such as those used to transport large volumes of resources and agricultural materials, such as grain, salt, coal, ore, sand, overburden and more.

\subsection{Roller}

A cylinder that rotates about a central axis and is used in various machines and devices to move, flatten, or spread something.

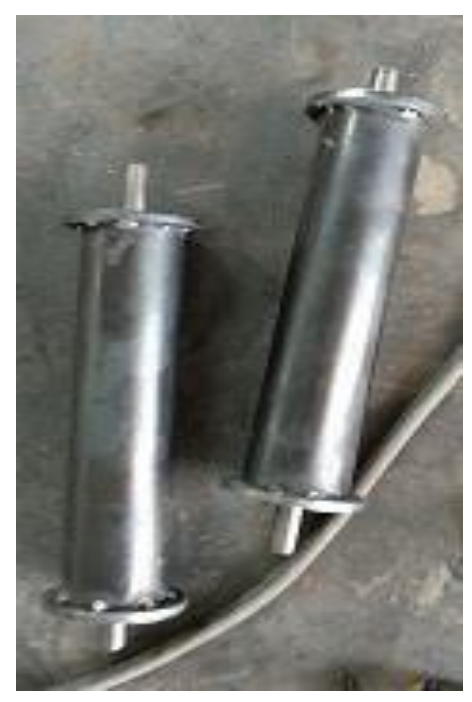

Figure 7 Rollers

\subsection{Gate Valve}

A gate valve, also known as a sluice valve, is a valve which opens by lifting a round or rectangular gate/wedge out of the path of the fluid. The distinct feature of a gate valve is the sealing surfaces between the gate and seats are planar, so gate valves are often used when a straight-line flow of fluid and minimum restriction is desired. The gate faces can be parallel, but are most commonly wedge-shaped. Gate valves are primarily used to permit or prevent the flow of liquids, but typical gate valves shouldn't be used for regulating flow, unless they are specifically designed for that purpose. 


\subsection{Drum}

Drum is a hollow casing attached with a number of blades and is connected to an AC motor. The paper content along with sufficient water is fed into the drum and the motor is switched on till the entire paper is converted to pulp.

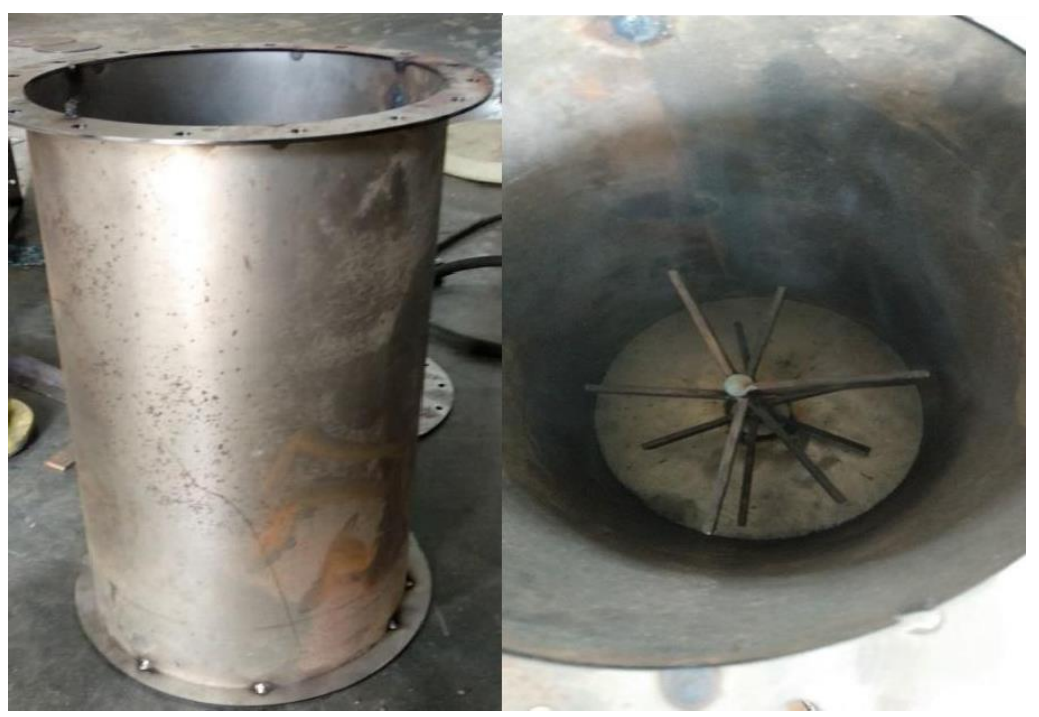

Figure 8 Drum

\section{PRODUCT DESCRIPTION}

\subsection{ServoMotor}

- VOLT: 12V D.C

- WATTS: 90W

- RPM: $60 \mathrm{RPM}$

\subsection{Battery}

- Material : Lead-Acid Free maintenance Battery

- Output Voltage : 12 V D.C

- Output Power : 40 Ampere-Hour

\subsection{Bearing}

- SIZE : 20 X 45 X 12 MM

- MATERIAL: STEEL

\subsection{AC Motor}

- VOLT : 230V A.C

- RPM : 1440 RPM

- CURRENT : 2.5A

- PHASE : 1 PHASE 


\subsection{Heater Specification}

- Coil wounded electric heater

- Coating: Ceramic coated

- Temperature: 400-500 deg Celsius

- Watts: 4000watts

- Voltage: 230v AC

- SINGLE PHASE AC

\subsection{Why? Mild Steel?}

The term 'mild steel' is also applied commercially to carbon steels not covered by standard specifications. Carbon content of this steel may vary from quite low levels up to approximately $0.3 \%$. Generally, commercial 'mild steer' can be expected to be readily weldable and have reasonable cold bending properties but to specify 'mild steel' is technically inappropriate and should not be used as a term in engineering. Mild steel is the most widely used steel which is not brittle and cheap in price. Mild steel is not readily tempered or hardened but possesses enough strength.

\subsection{Mild Steel Composition}

- Mild steel contains $-\mathrm{C} 45$

- Carbon 0.35 to $0.45 \%$ (maximum $0.5 \%$ is allowable)

- Manganese 0.60 to $0.90 \%$

- Silicon maximum $0.40 \%$

- Sulfur maximum $0.04 \%$

- Phosphorous maximum $0.04 \%$

- Mildest grade of carbon steel or mild steel contains a very low amount of carbon - 0.05 to $0.26 \%$

- Tensile strength $-63-71 \mathrm{kgf} / \mathrm{mm}^{2}$

- Yield stress $-36 \mathrm{kgf} / \mathrm{mm}^{2}$

- Izod impact valve min $-4.1 \mathrm{kgf} \mathrm{m}$

- Brinell hardness (HB) - 229

\section{WORKING PRINCIPLE}

The drum case consists of a Hydropulper. The function of the hydropulper is to convert the paper and water mix into the pulp. Working of Hydropulper - HydroPulper is a hollow cylindrical drum whose entire lateral surface is covered with a sieve-like mesh. The belt drive with pulley arrangement mounted below of the drum. It has rectangular slots cut onto its lateral surface to allow flowing of the sieve drum keeps rolling in the drum case continuously at very small speed. The drum was heated by heater circuits. The pulp slurry is fed to the small Vshaped collecting chamber which is a part of the drum case. As the drum is continuously rolling against the press roller (pick- up roller), the pulp gets stuck on the conveyor belt which is passes between the two drums. The conveyor belt rotates by the rotating motion of Dc 
motor. The pick-up roller is rubber coated to increase friction on its surface so as avoid slippage of the belt.

A large quantity of paper is fed into the drum first, then some amount of water is mixed in the ratio 2:1. Inside the Hydropulper, it consists of number of blades which is rotated with the help of a AC motor. The motor is turned on, and the blades start rotating in the drum.

After some time, thin paper pulp will be formed inside the drum with a rich water content. In order to reduce the water content, a heating coil is connected to the hydropulper. Hence the pulp inside the drum gets heated and water will be removed to an extent.

After the paper is fully converted to pulp, a valve is connected to the hydropulper is opened and hence the pulp is discharged into the belt conveyor. The belt conveyor is attached to two rollers at each ends and is operated using a DC motor.

With the help of the belt conveyor, the pulp is transferred onto a platform in a uniform manner. There the pulp is allowed to get dried. After a few moments the pulp will be dried completely and converted into thick form of paper or cardboard.

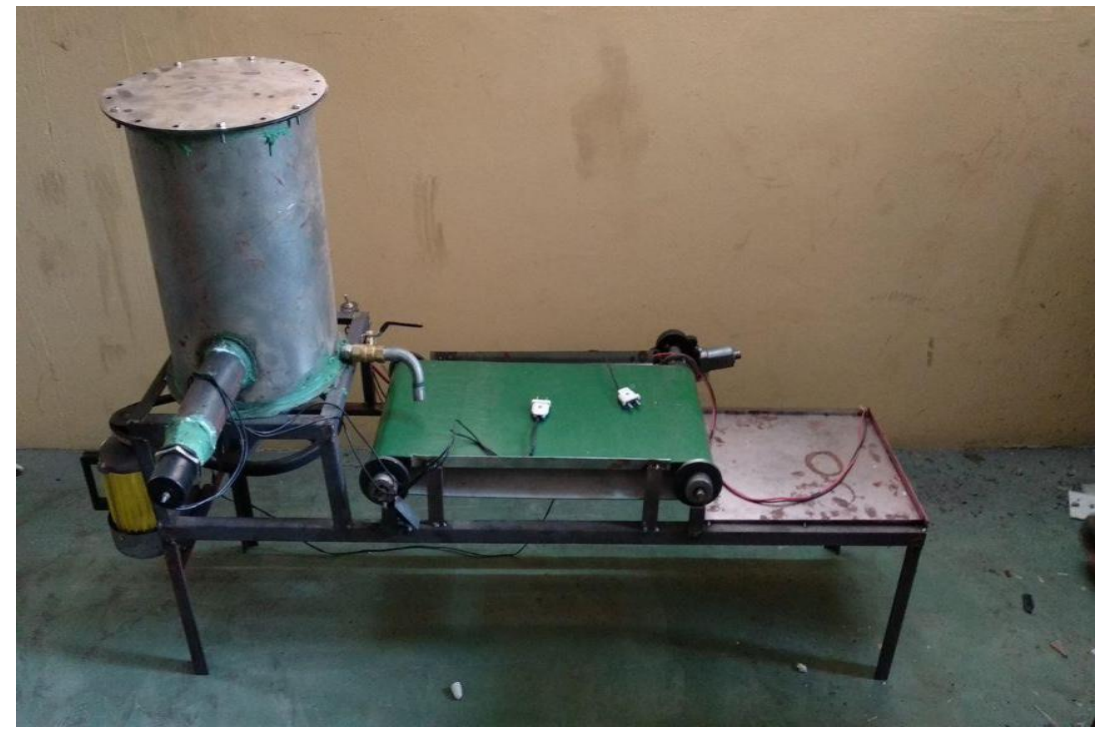

Figure 9 Model

\section{RESULTS}

The Design and Fabrication of the Paper recycling unit was done successfully. All the parts which include the AC motor, DC motor, Hydro-pulper unit are in proper working condition. The paper and water got thoroughly mixed and converted into fine pulp. The heating coil removed the excessive amount of water from the pulp content. The Pulp got deposited in the platform easily and was dried enough to get cardboard or paper of good thickness.

The Development of paper recycling unit is cheaper than automated recycling industries worldwide. The fabricated unit can serve dual purposes, it can be manned permanently at a stationary position or it could be shifted from one place to another. The cost of running is minimal.

The simplicity of operation of the unit ensures that not too much technical skill is needed to operate and durability is guaranteed. 


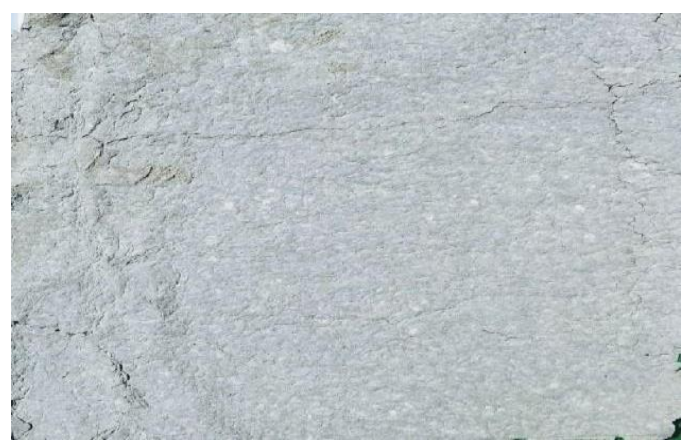

Figure 10 Final Product

\section{ADVANTAGES \& DISADVANTAGES}

\section{Advantages}

- The capital cost of the project is low.

- Increases production.

- Small in size and hence portable.

- The wastes that are produced from this machine are environmentally friendly and don't produce any harm to the environment.

- No need of skilled persons to operate the machine.

\section{Disadvantages}

- Regular maintenance is a must.

- Cleaning of the machine must be done periodically.

\section{APPLICATIONS}

These types of manually operated paper recycling machines have wide range of applications in the fields like,

- All sorts of small-scale industries,

- In all schools and colleges.

- Large offices and Companies.

- Pulp making industries.

\section{CONCLUSION}

This project work has provided us an excellent opportunity and experience, to use our limited knowledge. We gained a lot of practical knowledge regarding, planning, purchasing, assembling and machining while doing this project work. We feel that the project work is a good solution to bridge the gates between the institution and the industries.

We are proud that we have completed the work with the limited time successfully. The PAPER RECYCLING UNIT is working with satisfactory conditions. We can able to understand the difficulties in maintaining the tolerances and also the quality. We have done to our ability and skill making maximum use of available facilities.

In conclusion remarks of our project work, let us add a few more lines about our impression project work. Thus, we have developed a "PAPER RECYCLING UNIT" which helps to 
design a robot. In this project, we have combined the mechanisms of robotic and monitoring systems using an electronic control unit which actually moves and records the instants of the soil report and feeds it back to the control unit.

\section{FUTURE SCOPE}

- One of the underestimated industries.

- Huge Potentials and increasing demand.

- Government ranks $35^{\text {th }}$ in priority list.

- Growth rate expected to go from $8 \%$ to $10 \%$.

- Trees can be saved towards a large extent.

- Huge amount of paper waste can be reused and hence reduce waste generation.

\section{REFERENCES}

[1] Pulp and Paper Chemistry and Technology Volume 2, edited by Monica Ek, GöranGellerstedt, Gunnar Henriksson, De Gruyter Publications

[2] Akshya Paper Recycling Mill located at Karanja (LAD), Maharashtra.

[3] Kenneth W.B., Handbook on Pulp and Paper Technology, Second Edition, Van Nostrand Reinhold Co., New York, 1970.

[4] Carlson W. E. C., Recycle Process Inc. USA, PCT/US 91/03084, May 6, 1991.

[5] Discussion Paper on Collection and Recycling of paper in India

[6] Recycling Machine by M. A. OLUTOYE 